\title{
Pitching Baseball Across the Globe: The World Baseball Classic as MLB Marketing
}

\author{
By Roberta J. Newman*
}

\begin{abstract}
In this paper, I explore the World Baseball Classic (WBC) as a Major League Baseball (MLB) branding, marketing, and advertising initiative. Taking a socio-cultural approach, I pay particular attention to the WBC's inclusion of teams from Europe and China, where MLB has failed in past attempts to encourage both participation and spectatorship in baseball, as opposed to its successes traditional baseball markets such as the Dominican Republic and Japan. I consider television coverage and ratings as well as print advertising and other promotional material. Finally, I look at the WBC's social media presence and the role social media plays in promoting both the tournament and the game, in general. By these means, I attempt to discover whether MLB has been successful in growing the game and, thereby, creating a global baseball brand.
\end{abstract}

\section{Introduction}

On the evening of March 19, 2013, as the sounds of conga drums, air horns, and general merriment filled the air of San Francisco's AT\&T Park, the undefeated Dominican Republic emerged as champions of the third World Baseball Classic (WBC). Said Most Valuable Player, Robinson Cano, "This is for your country and comes from the bottom of your heart. We know how much our fans wanted it. This means the world to us. You know how it is back home." (Bloom, 2013). Their victory in the tournament represented a first for the Dominican team. So, too, was it a first for their opponents, the Puerto Rican team, which earned its spot in the finals by beating perennial WBC champions, Japan. That the tournament was a success in the three countries represented in the final round is evidenced by television ratings. In the Dominican Republic, the final game averaged an 11.9 rating and a 39 share, garnering an impressive 63 share--63 per cent of available viewers tuned in--in the final innings, making the game the highest rated single television event since 2003. In Puerto Rico, where the final game was broadcast on three different networks, Telemundo, MLB, and ESPN Desportes, it earned a 64 share. Expecting their team to defeat Puerto Rico the sudden death semi-final, Japanese fans were responsible for a 51 share (MLB, 2013).

Taken at face value, the WBC, which pits sixteen qualifying national teams against one another, is baseball's World Cup, a true World's Series.

*Faculty, Global Liberal Studies, New York University, USA. 
Like the FIFA World Cup, which has successfully promoted soccer, already the most popular sport in the world, in countries where baseball is the "national pastime,' the WBC is intended to excite interest in baseball in places where it has not yet caught on. But promotional enterprises like the WBC should rarely be taken at face value. The World Baseball Classic's stated mission is to encourage the global embrace of its sport. The true purpose of the WBC, however, is to spread the MLB brand. Doing so, the WBC aims to go beyond baseball's traditional Caribbean, Central American, and East Asian markets to reach out to new consumers, especially in Europe, South Africa, and China, places where soccer or, in the case of China, basketball, remain the dominant spectator sports.

In this paper, I explore the World Baseball Classic (WBC) as a Major League Baseball (MLB) branding, marketing, and advertising initiative. Taking a socio-cultural approach, I pay particular attention to the WBC's inclusion of teams from Europe and China, where MLB has failed in past attempts to encourage both participation and spectatorship in baseball, as opposed to its successes traditional baseball markets such as the Dominican Republic and Japan. I consider television coverage and ratings as well as print advertising and other promotional material. Finally, I look at the WBC's social media presence and the role social media plays in promoting both the tournament and the game, in general. By these means, I attempt to discover whether MLB has been successful in growing the game and, thereby, creating a global baseball brand.

\section{The World Baseball Classic}

Although the American baseball establishment has tried repeatedly to elicit global enthusiasm for its game, beginning as early as 1888 when sporting goods magnate and team owner, former pitcher Albert Goodwill Spalding staged his first World Tour, bringing baseball to Australia, Hawaii, Sri Lanka, Egypt, Italy, and France, among other places, attempts to internationalize baseball beyond its traditional boundaries have been met largely with indifference. An Olympic sport from 1992 until 2008, baseball was replaced by wrestling and squash after a 2005 by the International Olympic Committee (IOC). The official rationale for denying baseball its day in the Olympic sun derives from MLB's steadfast unwillingness to suspend its regular season so that its stars may participate in the global sports showcase. Also cited are MLB's previously unimpressive anti-doping policies, which the organization has gone to great lengths to correct. More importantly, the IOC vote indicates that baseball is not deemed significant or international enough in wider sports circles to be deserving of an Olympic berth (De Varona, 2013).

The first World Baseball Classic was initially staged in 2006 after the announcement of baseball's coming Olympic banishment. But the event was first conceived of in the mid-1990s. In contrast to participation in the International Baseball Federation World Cup, a little publicized tournament, or 
soon to be eliminated Olympic baseball, entry into the WBC was and continues to be by invitation only. By design, the WBC pits sixteen teams against each other in three rounds; the first is divided into four pools, playing in four widely scattered venues, the second into two, contested in the United States in Japan, respectively, and the third, a Championship round consisting of a semi-final and final game, in the United States. Overseen by Major League Baseball International (MLBI), an arm of MLB created with the express purposes of controlling all aspects the Major League product outside the organization's traditional sphere of influence--the United States and Canada--the WBC also differs fundamentally IBAF baseball, in that its national teams built are specifically built around marquee Major Leaguers, theoretically playing for their home countries. The WBC is, above all else, a Major League product.

Identifying big name stars to participate presents no problem for countries with rich baseball traditions and strong representation in the Major Leagues, such as Japan, South Korea, Mexico, the Dominican Republic, Puerto Rico, and Venezuela, for example. Teams from Chinese Taipei (Taiwan) and Australia also have a pool of Major Leaguers to draw upon, though hardly in the same abundance as the baseball powerhouses. But for teams from China, most participating European nations, South Africa, Brazil, and Israel, the Major League or Major League quality talent pool is thin to nonexistent. To counter this imbalance, eligibility has been granted not only to citizens and/or residents of participating countries, but also to players with one parent who was born in one of these countries. Those players able to prove that they would be eligible to apply for citizenship or a passport, should they desire to do so, at least hypothetically, may also participate (WBC, 2013).

For the 2013 edition of the WBC, MLB increased participation to twentyeight teams by adding another round-a qualifier that included twelve new countries as well as the four teams that failed to advance out of the first round of the 2009 WBC. Among the new participants were teams from the Czech Republic, France, and Germany, demonstrating the WBC's commitment to expanding in Europe. In addition to returning teams from Chinese Taipei and Canada, Brazil and Spain qualified to participate in the tournament for the first time.

\section{"Growing the Game"}

Clearly, MLB's mission in creating and staging the WBC is to spread its brand. But unlike FIFA, with its mission to "Develop the game, touch the world, build a better future," (FIFA, 1994), the WBC has no stated goal other than to showcase Major League players of various national origins, thereby exposing potential fans to the professional game as it is played at the highest level, at least from MLB's perspective. It does not take much, however, to see that MLB's motives are more complicated. According to Alan M. Klein:

Expanding the business opportunities of the game is critical, but 
within the larger framework of the industry, it is equally important to develop the game itself abroad. Major League Baseball has to deepen its roots where it already exists and engender interest where it is absent or exists only weakly: it must, in the business-inflected jargon of the organization, "grow the game." Hence MLBI is concerned with generating profits as well as with increasing the institutional popularity of the sport internationally. This requires a coherent view of the baseball world outside of the United States. (Klein, 2006).

It is specifically this coherent view of the baseball world, and, more importantly, its potential to generate profits by creating a new consumer base, that MLB aims to promote by means of the WBC.

\section{Major League Baseball's Brand}

It is clear that MLB seeks to "grow the game" and spread its brand globally via its international arm and the WBC. But how precisely does MLB intend to attract the attention of a world of fans already smitten by soccer and basketball to pay attention to a game so fundamentally different from these others: one that does not involve moving a ball up and down the field, one that has no clock, one in which the defense has the ball, one that sports columnist Dave Zirin calls "stubbornly provincial"? (Zirin,2007). More importantly what is MLB's brand?

"A brand," writes Melissa Davis, "is much more than a logo or a name. A brand represents the full 'personality' of the company and is the interface between an company and its audience. A brand may come into contact with its audience in various ways: from what we see and hear, through our physical experiences with the brand and general feeling or perceptions we have about a company. A brand encapsulates both the tangible and the intangible and can be applied to almost anything" (Davis, 2009). Specifically, notes Marieke de Mooij, a brand's personality is a combination of its brand identity, "the expression of the brand, including its name and visual appearance...the input by marketers, what they want consumers to take out," and the brand image, "the picture of the brand in the mind of the consumer" (de Mooij, 2010).

Perhaps more than any other sport, baseball's identity and its imageMLB's personality - are steeped in American history. Although the sport has been played in parts of East Asia and the Caribbean since the nineteenth century, the historic heritage MLB enthusiastically promotes and its fans embrace is purely that of the United States. Indeed, called the "national pastime" since 1856, baseball was considered to be America's game by the New York-based press long before its national spread, indeed, long before there was really a sense of the United States as a unified nation (Tygiel, 2001). Writes Jules Tygiel: 
Several commentators have argued with considerable supporting evidence, that the wish to create a "national game" stemmed from, in Melvin Adelman's words, a "desire upon the part of Americans to emancipate their games from foreign patterns. The Spirit [of the Times]called for a game "peculiar to the citizen of the United States, one distinctive from the games of the British like cricket or the German Turnverein. The New York Times in an article entitled "National sport and Their Uses" argued that "To reproduce the tastes and habits of English sporting life in this country is neither possible nor desirable." (Tygiel, 2001).

So essential was it to disconnect baseball from its English roots, to identify it as fundamentally American, that Alfred Goodwill Spalding, he of the 1888 World Tour, created the Mills Commission in 1905 to determine that the sport's origin. The result was what is now known as the Cooperstown Myth, asserting that baseball was invented single-handedly by Civil War General Abner Doubleday in Cooperstown, NY in 1839 (Tygiel, 2001). As Dain TePoel notes:

Baseball supposedly typified the best agrarian, democratic, educational and socially integrative features of American culture...fans and the public believed in the myths to assuage feelings of loss of an idyllic past and anxieties about the future. Supposedly, every white American male, at least, had the opportunity to excel and demonstrate his skill and talent on the field. These historical patterns, linking baseball and American Exceptionalism, survived and resonate in the early twenty-first-century US media narrative concerning international baseball. (TePoel, 2013).

Although more than a century has passed since the Mills Commission issued its highly suspect findings, the notion that baseball is a fundamentally American game, rooted in a mythic, agrarian past and deeply democratic at its core, has endured. One need only look at MLB's logo, a white batter silhouetted against a field of red and blue, to see its connection to the idea of America. After all, only an organization deeply invested investment in the image of America would circulate a petition to the US government to make Opening Day a national holiday, albeit in conjunction with an advertising initiative with equally American-branded Budweiser (actually owned by Belgium brewing giant, $\mathrm{AB}-\mathrm{InBev}$ ). Even the increasingly international nature of its player-base does not contradict from the MLB's purely American brand personality. The very notion that players from Latin America, Japan, Korea, and Taiwan, for example, can become big league stars reinforces MLB's democratic, "if you can make it here, you can make it anywhere" brand of Americanism.

In order for MLB to be truly successful in globalizing its product, it must make steps to broaden the historic and geographic components of its brand 
personality, taking specific steps to appeal to European and Chinese audiences. According to Benjamin J. Goss, an essential dimension of all global brands is the "capability to create a shared global identity that gives consumers a perceived cosmopolitan lifestyle, known as global myth, in which they share an imagined global identity with likeminded people, feel a sense of belonging to something bigger, and ascribe to desired qualities." In these terms, in order for MLB to "grow the game" through the WBC, it must essentially create a baseball culture apart from its traditional culture by cultivating a class of consumer citizens, ready to vote for the MLB branded tournament with their dollars. But how are they to do this? Goss suggests that MLB has already taken steps to perpetuate the Global Myth by signing sponsorship deals with globally recognizable brands (Goss, 2009). Indeed, the WBC counts among its sponsors Delta airlines, DiscoverAmerica travel promotion, Konami digital gaming, and MetLife insurance, all companies with international recognition, if not truly global brands.

But contrary to Goss's assertion, simply signing globally recognizable sponsors is not enough to aid in the creation of a new baseball culture. Certain global corporations, international banking and investment company such JP Morgan Chase or the Industrial and Commercial Bank of China, for example, might not serve the desired purpose of contributing positively to the image of a new global baseball community. It is not that there is anything wrong, per se, with international finance. Rather, the meaning of international finance might not gel coherently with the message MLB aims to convey. According to Grant McCracken, "Consumer goods have a significance that goes beyond their utilitarian character and commercial value. This significance rests largely in their ability to carry and communicate cultural meaning." He continues:

Usually, cultural meaning is drawn from a culturally constituted world and transferred to a consumer good. Then the meaning is drawn from the object and transferred to an individual consumer. In other words, cultural meaning is located in three places: the culturally constituted world, the consumer good, and the individual consumer, and moves in a trajectory at two points of transfer: world to good and good to individual." (McCracken, 1986).

If, as Goss suggests, MLB must draw upon the global myth to create a new, coherent baseball culture, then the respective meanings of its corporate sponsors will necessarily transfer through the WBC to its nascent community of global baseball consumers. In order to be successful, these meanings must contribute qualities extrinsic to the game of baseball, but appropriate to the brand personality. It is easy to see how Delta, DiscoverAmerica, and Konami accomplish this. After all, both are corporations that sell travel, and travel is fundamental to both baseball and its global brand. Konami Digital Entertainment, too, contributes positively to MLB's global brand. As the creators of video games such as Castelvania and Metal Gear Solid as well as the $Y u$ Gi Oh trading card game and videos, Konami attaches technical savvy, 
up-to-datedness, and youthfulness to a sport with a reputation of being slow, hide-bound to tradition, and appealing primarily to older spectators. Konami also produces the Pro Evolution Soccer video game. As such, it also connects the meanings associated with soccer to MLB through the WBC.

MetLife's connection to baseball is, in contrast, considerably more tenuous. Unlike international finance, which may be too large, impersonal, powerful, and inaccessible to transfer the appropriate meanings through the WBC to consumers, insurance deals with consumers on an individual basis. MetLife is, by its very nature, personal and accessible. Nevertheless, it is hard to see what meanings insurance contributes to the MLB brand. Addressing the vagueness of the connection, albeit tangentially, the insurance giant has done a little branding of its own, naming Snoopy, sometime World War I flying ace and star baseball player from the Peanuts comic strip, itself a global brand, as its "brand ambassador." Indeed, on Thursday, February 28, 2013, Snoopy--or a person in a Snoopy suit and a WBC jersey--rang the opening bell of the New York Stock Exchange to mark the opening of the tournament, thereby transferring the meaning of Wall Street to MLB through the WBC on an accessible level, as well as all the playfulness associated with the comic strip. MetLife also sponsors the All-World Baseball Classic team promotion, allowing fans to vote for to place their favorite players from the tournament on a symbolic dream team, thereby transferring the meaning of global baseball onto global baseball, itself.

As global sponsors of the WBC, each with its own set of meanings, Konami, Delta, DiscoverAmerica, and MetLife also have a very powerful meaning in common. Even as globally recognized brands, each is inextricably associated with its country of origin. MetLife, with Snoopy at the helm, Delta, and DiscoverAmerica are all intimately connected with the idea of America. And Konami's anime aesthetic is purely Japanese. So while these are certainly globally recognized sponsors and thereby contribute to the Global Myth, they do not necessarily change MLB's brand personality. After all, MLB, by its very nature, has already transferred its traditional meaning of "Discover(ing) America" on to its consumers via the WBC, and given the dominance of the Japanese national team in the tournament, the WBC already means "Japanese gaming.

Moreover, the meanings transferred with national origin may be others than those intended by either the sponsors or the MLB brand. Di Mooij notes:

This can be beneficial if the image of the country remains constant. In case of change, both upgrading (Japan from "shoddy" to "high quality") and downgrading (e.g., political activities by the country of origin) may influence the brand's image and acceptance. "America values" may temporarily have become ambiguous; for some they are positive, for others negative. However, in spite of accusations of American cultural imperialism, there is little evidence of broad-scale rejection of American brands. Most global consumers appear to separate the United States, including American values, from 
American brands. A key reason is the fact that many brands have transcended their "American-ness." (di Mooij, 2011)

But MLB is not Coca Cola, nor is it Nike or Apple. It is a brand that, by its very nature, promotes American values and cannot be separated from them, even if its WBC has non-American sponsors like Konami. While Chinese consumers might react favorably to the Americanism of MLB, as they have to the NBA, particularly if MLB is able to secure and promote a Chinese star player, European consumers may not necessarily regard Americanism as an asset. In the same regard, given China's attitudes toward what it perceives to be Japanese cultural and political imperialism, both past and present, Konami's meaning as a corporate sponsor may be also be problematic. Of course, the solution to this dilemma would be to court European and Chinese global sponsors for the WBC. MLB did hire German-based ITMS to handle sponsorship deals for the 2013 tournament, but European global sponsors for the event appear to have been in short supply.

\section{Audience}

Of course, securing globally recognizable corporate sponsors is not the only way for MLB to promote the WBC. Goss notes that building global sports brands, "typically involve movement in three primary areas: development of the live audience size and/or experience, development of the media-based audience size and/or experience, and the expansion for related merchandise, sporting goods, and licensed items" (Goss, 2009). Indeed, it is in these very areas that the MLB claims some success. According to mlb.com, attendance figures for WBC games "shattered attendance records," reaching a total of 885,203 of tickets sold for all the 2013 venues. This suggests that a live audience for the WBC already exists. And licensed merchandise sales in these locations was up ten per cent from those of previous tournament. But these figures are somewhat misleading, given the fact that the tournament was contested only in locations baseball already has a strong foothold, most specifically, Puerto Rico, Japan, and the United States. Attendance for the 2013 qualifying rounds, however, was inconsistent. A match between France and Spain played at Roger Dean Stadium in Florida, for example, drew only 975 paying spectators, and a game between the home team and Canada at Armin Wolf stadium in Regensburg, Germany, drew 4085 to the 10,000 seat venue. And while the attendance figures for Rod Carew Stadium in Panama City, Panama, are more robust - a game between the home team and Brazil drew 10,368 - given the fact that the venue seats 28,000, no records appear to have been set in Panama, either (BR Bullpen, 2013).

No matter how many paying fans attended the WBC, most of the audience enjoyed the tournament not in person, but by means of mass media. As the television ratings for WBC powerhouses Japan, Puerto Rico, and the Dominican Republic demonstrate, there is already substantial interest in the 
tournament outside the United States, where attendance is excellent but viewership is low. In Taiwan, where baseball is also popular, ratings were also impressive; the extra-innings match between Chinese Taipei and Japan was the second highest rated cable broadcast in Taiwanese television history, as reported by mlb.com. But in the European countries MLB has targeted for expansion, only Spain, the Netherlands, and Italy - all of which boasted teams that qualified for the 2013 tournament-even had dedicated broadcast networks airing WBC games. Of the European teams that participated in the 2012 qualifying round but that did not advance, France, Russia, the Czech Republic, Germany, and Great Britain, not one appears to have broadcast the WBC locally. Of course, ESPN provided some international coverage, but its broadcasts were all English language affairs aimed, for the most part, at American sports fans, not a local audience. In China, a market MLB is determined to enter, there was little or no coverage of the WBC. GDTV, a Guangdong-based network, is listed as a media partner on the WBC website, but it did not offer live broadcasts of the Chinese team's games in the first round of the 2013 tournament. In fact, the tournament was completely ignored by English and even Japanese language sports channels in China, as well.

\section{Social Media}

While traditional television coverage has done little to promote the WBC and to spread the MLB brand beyond traditional baseball markets, MLB has been successful in the area of social media. According to mlb.com, the 2013 WBC generated almost 600 million social media impressions, that is, references to the WBC were seen almost 600 million times on social media sites. But this number is deceiving, because the metric only refers to the number of times a reference is seen, not the number of times the viewer actually engages with the message. Nevertheless, MLB also reports that in excess of seventy five terms related to the 2013 tournament trended worldwide on Twitter during the WBC. Most notably, at certain points during the Championship round, which included the semifinal game between the Netherlands and the Dominican Republic, every top trend in the countries involved was somehow connected to the WBC (MLB, 2013). This suggests that while viewership may not have been high, there was local interest in the Dutch team, at the very least.

\section{Conclusions}

What is to be learned from the 2013 attendance figures, television ratings, and social media impressions? All the tweeting from the Championship round, the impressive television ratings in Japan, Taiwan, Puerto Rico, and the Dominican Republic, and strong attendance figures for the three-round tournament point to one important factor in global interest in the WBC. 
Membership in the global MLB community appears to be motivated, above all else, by nationalism or at least by nationalist impulses. This assertion is clearly supported by attendance figures from the qualifying rounds. In Taiwan, for example, the game between the Philippines and Thailand drew only 923 spectators, while when the same Philippine team played home team Chinese Taipei, more than ten times the number of fans attended. And at Roger Dean stadium, a minor league ballpark with a capacity of 6,800 , only the match between Israel and Spain, which was well attended, drawing 4,463, attracted more than 1,200 fans. This can be explained by the presence of a large JewishAmerican population in the vicinity that identified ethnically with the Israeli team (BR Bullpen, 2013). Given MLB's desire to emulate FIFA's World Cup, the connection with nationalism and fandom should not be at all surprising. Indeed, nationalism seems to drive fandom in most international competition, even the Olympic games.

Is nationalistic fandom necessarily a bad thing? Certainly, when it leads to violence, it is. But baseball fans, though prone to occasional outbursts, are notably peaceful. Indeed, the community-based agrarian aspects of the MLB brand almost assure that nationalistic impulses are expressed in an appropriately peaceful manner. All spectator sports thrive on rivalry. Harnessing nationalistic impulses or, at the very least, national pride, may be the most efficient way to build a dedicated fan base. Creating new national rivalries, for example, like the one between the United States and Canada in Olympic Women's Hockey, thereby creating emotional attachments to national teams, may serve to promote the WBC on a global level. Excitement over the 2009 final between Japan and South Korea certainly bears this out. And rivalries based on national pride need not be so fraught as this particular example. Indeed, as MLB's homegrown rivalries prove, proximity also provides fertile ground for rivalries, such as the aforementioned Olympic hockey rivalry. Certainly, creating proximity-based rivalries might work in Europe to create a new class of baseball consumers, members of MLB's new global baseball community.

Has the WBC be successful as a tool to spread baseball at the same time it promotes the MLB brand? As of yet it has not. Until it can find a way to divest itself of its tradition-bound American image, albeit one tinged with both a Japanese and Latin flair, MLB is likely to fail at creating a new global baseball community, where consumers from non-traditional baseball markets eagerly adopt the game as their own, in the same way fans from around the world have adopted that other English game, football. Whether MLB does so by means of meaning transfer from global sponsors to potential consumers, by developing players from target markets, or by some other means, MLB must figure out how to grow its brand personality before it can grow the game. 


\section{References}

Bloom, Barry M. Domi- nation: DR runs table en route to title, World Baseball Classic (March 20, 2013). http://web.worldbaseballclassic.com/2013/news/arti cle.jsp?ymd=20130319\&content_id=42998208, (March 21, 2014).

BR Bullpen, 2013 World Baseball Classic Qualifiers (2013), BaseballReference.com. http://www.baseball-reference.com/bullpen/2013_World_Base ball_Classic_Qualifiers (April 19, 2014).

Davis, Melissa. The Fundamentals of Branding. Lausanne, Switzerland: AVA Publishing, 2009.

De Varona, Donna. Another strikeout for softball (September 9, 2013), http://espn.go. com/espnw/news-commentary/article/9654700/espnw-another-olympic-strikeoutbaseball-softball (March 22, 2014)

di Mooij, Marieke. Global Marketing and Advertising: Understand Cultural Paradoxes. London: Sage, 2010.

FIFA, Our Mission, About FIFA (1994), http://www.fifa.com/aboutfifa/organisa tion/mission.html (March 20, 2014).

Goss, Benjamin D, "Taking the Ballgame Out to the World: An Analysis of the World Baseball Classic as a Global Branding Promotional Strategy for Major League Baseball." Journal of Sport Administration and Supervision, Volume 1, Number 1 (April 2009):75-95.

Klein, Alan M. Growing the Game: The Globalization of Major League Baseball. New Haven, CT, USA: Yale University Press, 2006.

McCracken, Grant. Culture and Consumption: A Theoretical Account of the Structure and Movement of the Cultural Meaning of Consumer Goods. Journal of Consumer Research, Volume 13, Number 1 (June, 1986): 71-84

McDonnell, Wayne G., Jr. (March 20, 2013), Nationalism overshadows apathy at the conclusion of the World Baseball Classic, forbes.com, http://www.forbes.comsi tes/waynemcdonnell/2013/03/20/nationalism-overshadows-apathy-at-the-conclu sion-of-the-world-baseball-classic/ (April 17, 2014).

MLB Press Release, World Baseball Classic grows baseball globally with recordsetting 2013 tournament, http://mlb.mlb.com/news/article.jsp?ymd=20130321\& content_id=43072146\&vkey=pr_mlb\&c_id=mlb (March 22, 2014).

Ressler, William Harris, Ian Rebhan, Jesse Goldberg-Strassler, "Is This Heaven? It's Iowa (strike through) the World Baseball Classic: "Field of Dreams" Moments in Global, Domestic, and Internal Marketing. NINE: A Journal of Baseball History and Culture, Volume 22, No. 1 (Fall, 2013): 78-102

TePoel, Dain. Pastime or Waste of Time: Narratives in the Media Surrounding the 2006 World Baseball Classic. NINE: A Journal of Baseball History and Culture, Volume 22, Number 1 (Fall 2013) 52-77.

Tygiel, Jules. Past Time: Baseball as History. New York: Oxford University Press, 2001.

Wallace, Bruce. Japan Might Balk at this Brand-New Ballgame, Los Angeles Times, June 13, 2005, D8.

Williams, Carol J. and Tim Brown, "Cuba is Back in the Game," Los Angeles Times, January 21, 2006, D1.

World Baseball Classic, Eligibility, World Baseball Classic Tournament Rules and Regulations, http://web.worldbaseballclassic.com/wbc/2013/about/rules.jsp\#eligi bility (March 20, 2014).

Zirin, Welcome to the Terrordome: The Pain, Politics, and Promise of Sports. Chicago: Haymarket Books, 2007. 
